ual looseness of his conduct with women. $\mathrm{He}$ made no attempt to conceal his amused incredulity when I charged this vice with being largely responsible for bis nasal discomfort, but he agreed nevertheless to give virtue a month's trial. Not to rob this remedy of any possible credit, all other treatment was for the time suspended. Brief as it was, the period of proba. tion proved more than sufficient to vindicate my faith in the prescription, and $I$ was able to dismiss my patient with the assurance that his best safeguard against future return of this trouble, would be a rigid observance of the spirit as well as the letter of the Seventh Commandment. It is always my endeavor to be as sparing as possible in the use of drugs, but in cases such as this, where from long disuse, self-control has undergone a shameful enfeeblement, the bromids or any of the other anaphrodisiacs may be utilized to dull the vicions appetite, until sufficient will power is regained to completely conquer it.

$$
\text { Discussion. }
$$

Dr. Mackenzie-The relationship between over-indulgence of the sexual powers and morbid conditions of the throat, eye and ear has been recognized from a very early period. The fact is about as old as literature itself, but the pathologic relation between the nose and the reproductive apparatus is a matter of recent recognition. The first attempt to reduce the subject to a scientific basis was made by me some fifteen or sixteen years ago, and I subsequently published the result of my observations in the American Journal of Medical Sciences for April, 1884. Subsequent observations made, among others, by Arviset, Ischwell and Joal in France and by Peyer, Endries and Fliess in Germany have only served to sustain the positions taken in my original essay. Fliess has written a very elaborate monograph on the subject. The phenomena observed furnishes food for reflection not only for the physiologist and pathologist, but also for the biologist. In contemplating them, we are brought face to face with a most interesting enigma-a problem of life whose biologic significance it must be the task of the future to divine. Dr. Grayson's cases furnish additional corroborative evidence of a most important physiologic relationship.

\section{DIFFICULT DEFECATION IN INFANTS.}

Presented in the Section on Diseases of Children, at the Forty-eighth Annual Meeting of the American Medical Association, beld at Philadelpbia, Pa., June 1-4, 1897,

BY THOS, CHAS. MARTIN, M.D.

Lecturer on Diseases of the Rectum in the Cleveland College of Physicians and Surgeons (Medical Department of the Ohio Wesleyan

University), Surgeon for Diseases of the Rectum in the Cleveland General Hospital, Member of the American Medical Association, Member Ohio State Medical Society, Mem-

ber Cleveland Medical Society, Member Cuyahoga County Medical Society, etc. ClEveland, OHIO.

I should be unmindful of the history of human experience should I harbor the hope that the several affirmations set forth in this paper would be accepted without disagreement by a body of medical men. Remembering, however, that there is very little progress in knowledge except along lines where soundest casuists doubt, I propose for discussion the problem of difficult defecation in infants.

It is generally recognized that infants strain at stool.

The infant strains at stool because of the imperfect development of the anatomic features concerned in the mechanism of expulsion. These are as follows:

1. The infant's lower gut is muscularly deficient.

2. Its mobility within the abdomen is obstructive to defecation.

3 . The rectal valves are obstructive.

4. The infant's anus not being sufficiently expansible is also obstructive.

The specimens of infant recta and sigmoid here shown are the first taken in my research on this subject, and are fairly illustrative of the facts upon which the foregoing declarations are based. The large specimens examined are those of adults and are typical.

The dried specimerss shown in plates 3, 5, 7, 9 and 20 , were prepared by flushing the intestine and then fixing the subject in the genu-acromial posture; the anus was then fixed open and melted paraffin was injected under about twelve ounces pressure. When hardened that portion of the gut occupied by the cast was removed ${ }^{1}$. Specimens shown in plates 11 and 12 were prepared by placing the subject in the dorsal decubitus and by opening the descending.colon; the intestine below was then washed out and the colon perforation fixed at the abdominal wound, which save for this point was sewed up, the anus was tied up and as much melted peraffin as would enter under two pounds' pressure was forced into the gut; subsequently the sigmoid and rectum were removed as in the other cases. After immersion in alcohol the specimens were varnished.

The following are the memoranda of the autopsies made in this study:

Case 1.-Female, still-born; height 16 inches $(40.64 \mathrm{~cm}$.$) ;$ circumference at anterior superior spinous process $71 / 2$ inches $(19.05 \mathrm{~cm}$. ) ; anterior superior spinous process diameter 3 inches $(7.62 \mathrm{~cm}$.) ; ensiform to pubes 4 inches $(10.16 \mathrm{~cm}$.); transverse diameter pelvic outlet $3 / 4$ inch $(1.90 \mathrm{~cm}$.); peritoneum at last vertebra of coccyx. (Plate 3.)

Case 2.-Female, age 1 hour, height 17 inches $(43.18 \mathrm{~cm}$.); circumference at anterior superior spinous process $71 / 2$ inches $(19.05 \mathrm{~cm}$.); anterior superior spinous process diameter $21 / 2$ inches $(6.35 \mathrm{~cm}$.$) ; ensiform to pubes 4$ inches $(10.16 \mathrm{~cm}$.$) ;$ transverse diameter pelvic outlet $1 / 2$ inch $(1.27 \mathrm{~cm}$.); peritoneum at last vertebra of coccyx. (Plate 5.)

Case 3.-Male, age 1 month, height 23 inches $(58.42 \mathrm{~cm}$.); circumference at anterior superior spinous process 9 inches $\left(22.86 \mathrm{~cm}\right.$.); anterior superior spinous process diameter $3 \frac{1}{2}$ inches $(8.89 \mathrm{~cm}$. ) ; ensiform to pubes 4 inches $(10.16 \mathrm{~cm}$. $)$; transverse diameter pelvic outlet $5 / 8$ inch $(1.59 \mathrm{~cm}$.); peritoneum at last vertebra of coccy $x$.

Case 4. Female, age 6 weeks, height 24 inches $(60.96 \mathrm{~cm}$.); circumference at anterior superior spinous process $10 \%$ inches (26.67 cm.) ; anterior superior spinous process diameter 3 inches $(7.62 \mathrm{~cm}$.); ensiform to pubes $51 / 2$ inches $(13.97 \mathrm{~cm}$.); transverse diameter pelvic outlet $5 / 3$ inch $(1.59 \mathrm{~cm}$.); peritoneum at last vertebra of coccyx. (Plate 9.)

Case 5.-Female, age 2 months, height 20 inches $(50.80 \mathrm{~cm}$.); circumference at anterior superior spinous process 8 inches $(20.32 \mathrm{~cm}$.); anterior superior spinous process diameter 3 inches $(7.62 \mathrm{~cm}$.); ensiform to pubes $31 / 2$ inches $(8.89 \mathrm{~cm}$.); transverse diameter pelvic outlet $3 / 4$ inch $(1.90 \mathrm{~cm}$.); peritoneum at last vertebra of coccyx. (Plate 20.)

Case 6.-Male, age 6 months, height 24 inches $(60.96 \mathrm{~cm}$.); circumference at anterior superior spinous process 10 inches $(25.40 \mathrm{~cm}$.); anterior superior spinous process diameter 4 inches $(10.16 \mathrm{~cm}$.); ensiform to pubes 5 inches $(12.70 \mathrm{~cm}$.); transverse diameter pelvic outlet ${ }_{-}^{3}$ inch $(1.90 \mathrm{~cm}$.); peritoneum at last sacral vertebra. (Plate 11.)

Case 7.-Male, age 6 months, height 24 inches $(60.96 \mathrm{~cm}$.$) ;$ circumference at anterior superior spinous process 12 inches $(30.48 \mathrm{~cm}$.); an terior superior spinous process diameter 4 inches $(10.16 \mathrm{~cm}$.) ; ensiform to pubes 5 inches $(12.70 \mathrm{~cm}$.); transverse diameter pelvic outlet ${ }^{3}$ inch $(1.90 \mathrm{~cm}$.); peritoneum at first bone of coceyx. (Plate 12.)

Case 8.- Male, age 17 months, height 25 inches $(63.50 \mathrm{~cm}$.); circumference at anterior superior spinous process 12 inches $(30.48 \mathrm{~cm}$.$) ; anterior superior spinous process diameter 4$ inches (10.16 cm. ); ensiform to pubes 6 inches $(15.24 \mathrm{~cm}$.) ; transverse diameter pelvic outlet 1 inch $(2.54 \mathrm{~cm}$. ); peritoneum at last sacral vertebra. (Plate 7.)

Examination of the pictures of the dried specimens reveals that the wall of the infant rectum and sigmoid flexure is thin compared to that of the adult. (See plates $3,5,7,9$ and 20.) It is impossible to distin-

1 For more particular description of the method of preparation see paper by the writer In Mathew's Quarterly Journal of Rectal and Gastrointestinal Diseases, $\mathrm{July}, 1896$. 


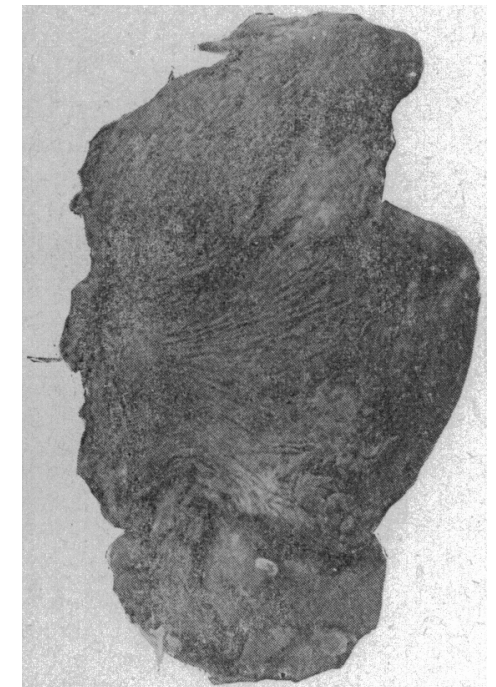

FIg. 1.-The rectum of an adult; muscular bands are seen to be well developed. Filled in the procto-colonoscopic posture.

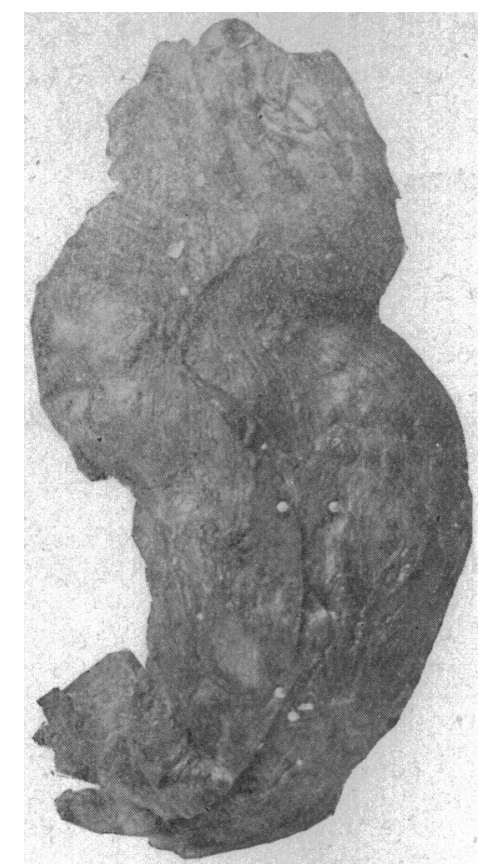

FIG. 2.-The rectum of an adult; muscu lar bands are seen to be well developed. Filled in procto-colonoscopy.

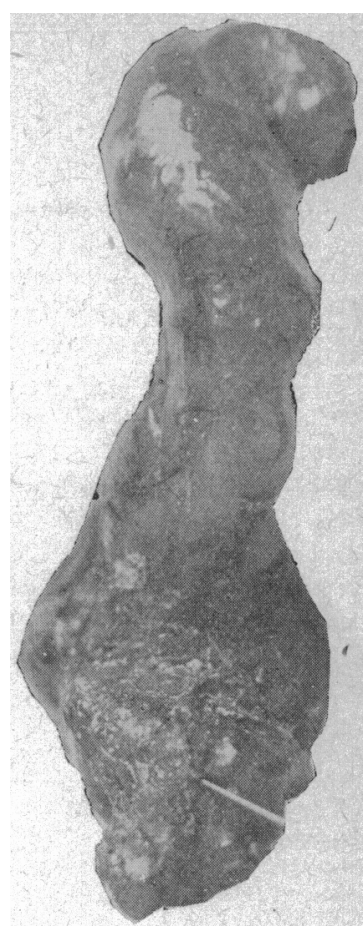

FIG. 3.-The rectum of an infant, stillborn; muscular coat undeveloped. Filled from below.

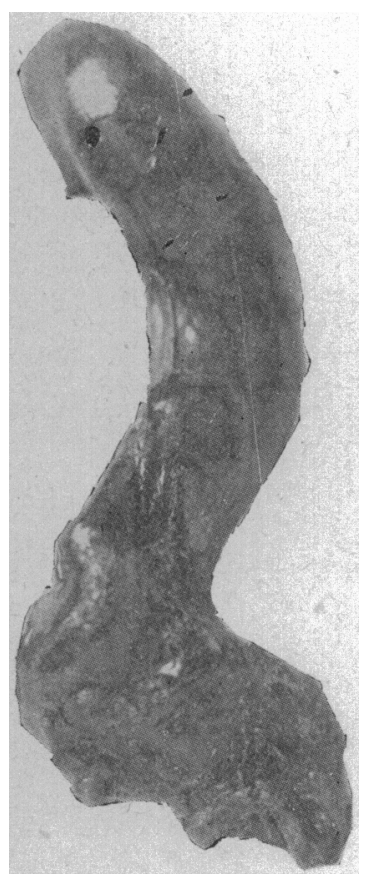

FIG. 4.-Side view of the specimen shown in rig. 3 . Antero-posterior angulation at third sacral vertebra.

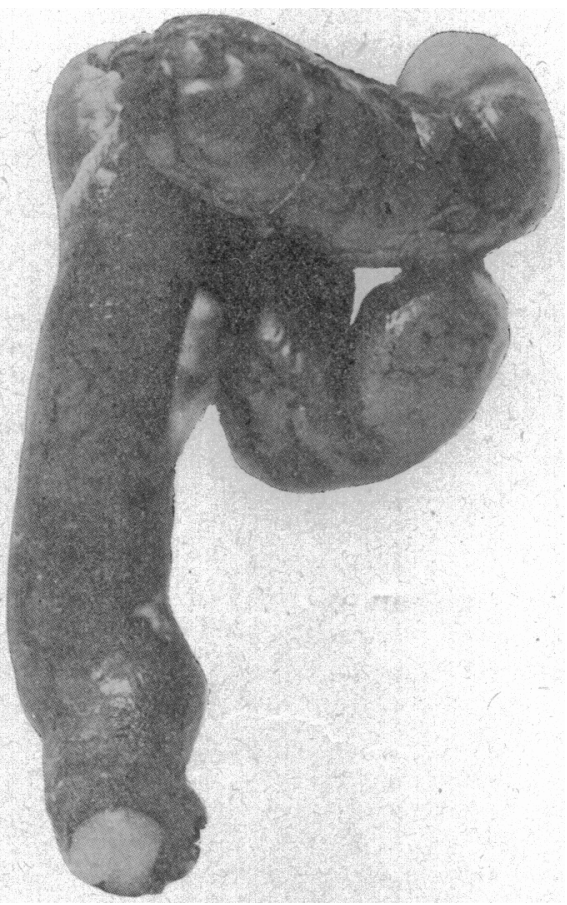

FIG. 5.-Front view of the rectum of an infant aged one hour, autopsy while in a state of rigor mortis. The rectum being state of rigor mortis. The rectum being

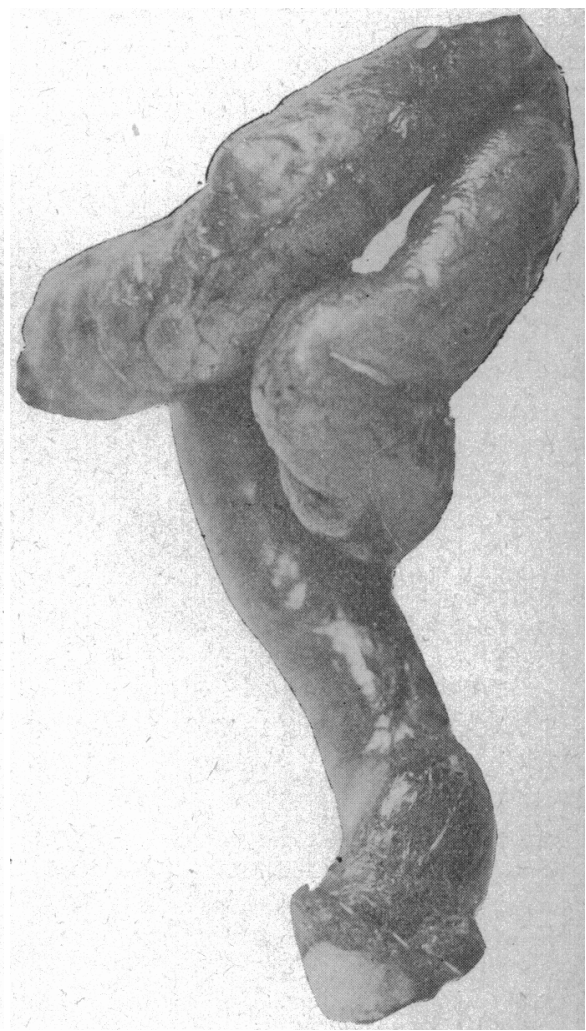

FIg. 6.-Side view of the specimen shown in Fig. 5 .

guish the longitudinal muscular bands which are so the adult. The infant gut is very deficient in muscuapparent in the gut of the adult. (See plates 1, 2, lar elements, therefore the intrinsic power of peristal17.) In the fresh state the mucous membrane con- sis can not be present in that degree necessary to it as stitutes a great part of the thickness of the gut wall a component factor of defecation.

of the infant, and the mucous membrane and mus- The relations of the peritoneum to the rectum of cular coats are more intimately adherent than in the infant, also contribute to the difficulties of defeca- 


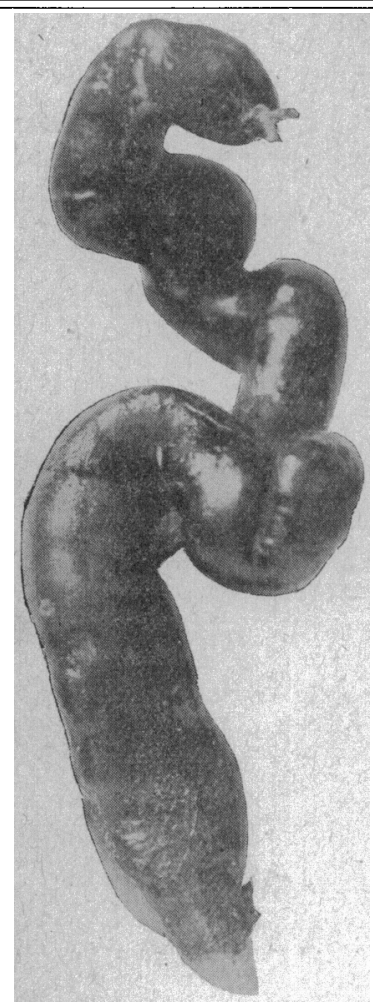

FIg. 7.-Front view of the rectum of an infant aged one month; autopsy while in a state of rigor mort

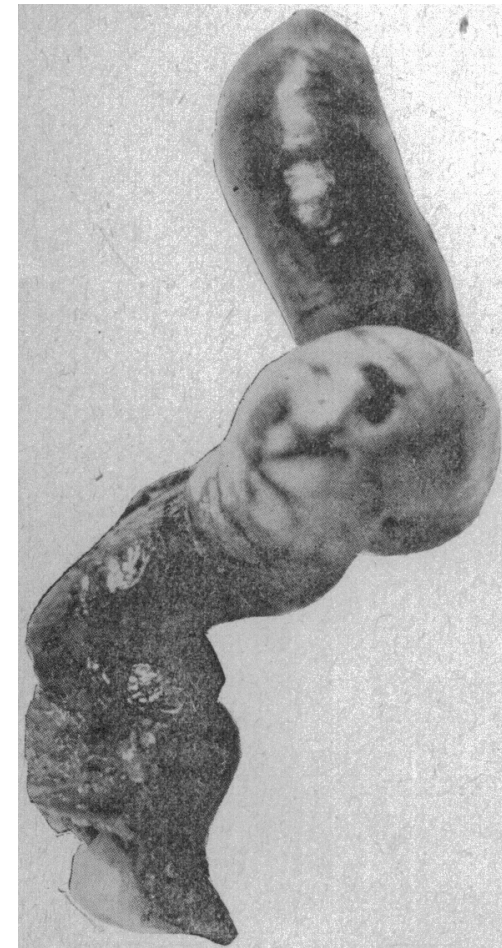

Frg. 10,- Side view of the specimen shown in Fig. 9.

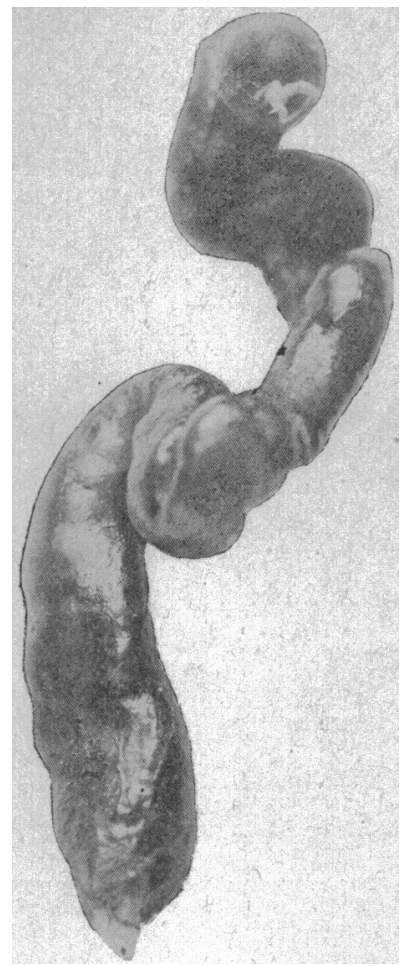

Fig. 8.- Side view of the specimen shown in FIG. 7 .

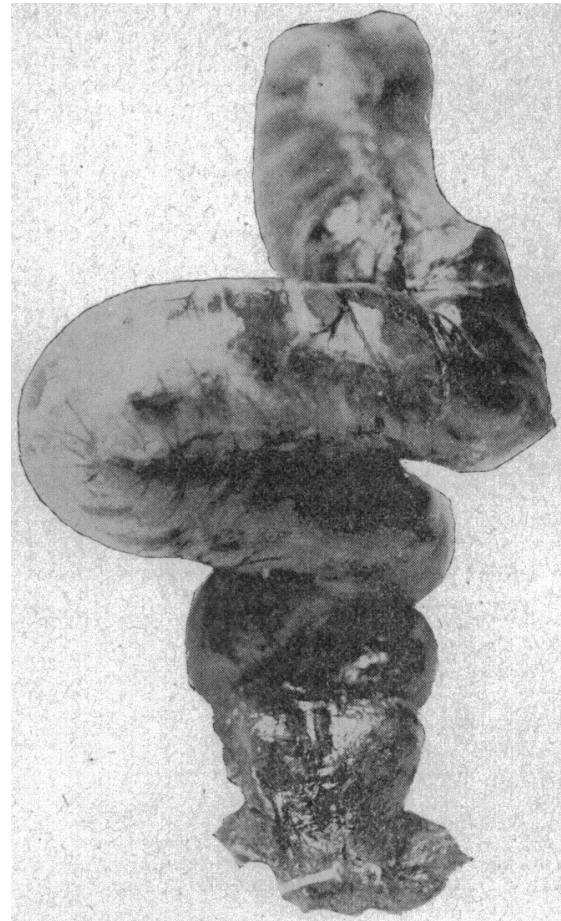

FIg. 9-Front view of the rectum of an infant aged six weeks. Filled from below.

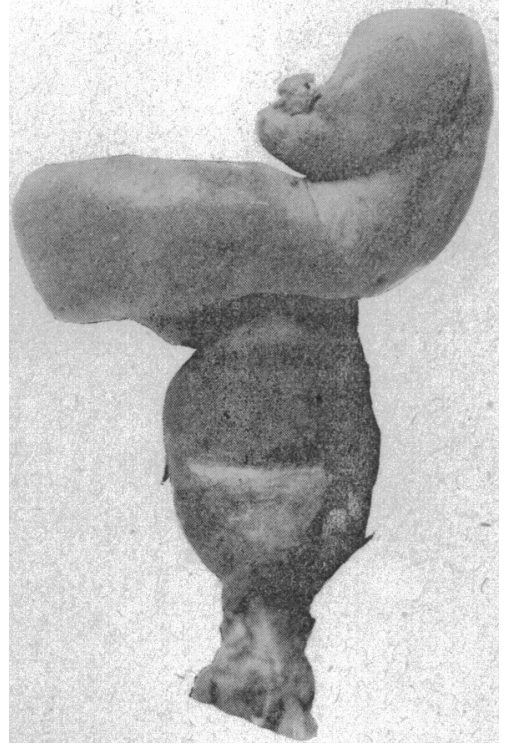

FIG. 11.-Front view of the rectum of an infant aged six months. Filled from above infant aged six months. Filled from above

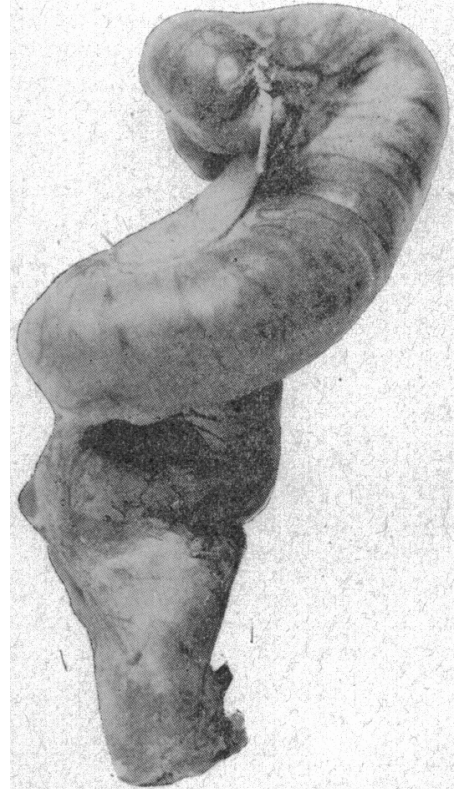

Frg, 12.-Front view of the rectum of an nfant ared six months. Filled from above after disappearance of rigor mortis.

tion, as also does the relatively great length of the |distance from the promontory of the sacrum to the descending colon and sigmoid flexure.

distal bone of the coccyx. (See plates 13, 14.) From

In the child the mesentery of the sigmoid flexure the sigmoido-rectal juncture to the beginning of the and rectum is disadvantageously long. In young middle third of the rectum the mesentery rapidly children the length of the sigmoidal mesentery from shortens but apparently completely invests the upper its attachment to the parietes to its invagination of third of the rectum. The middle and lower thirds are the lower loop of the sigmoid is often greater than the not so completely invested and present upon their 


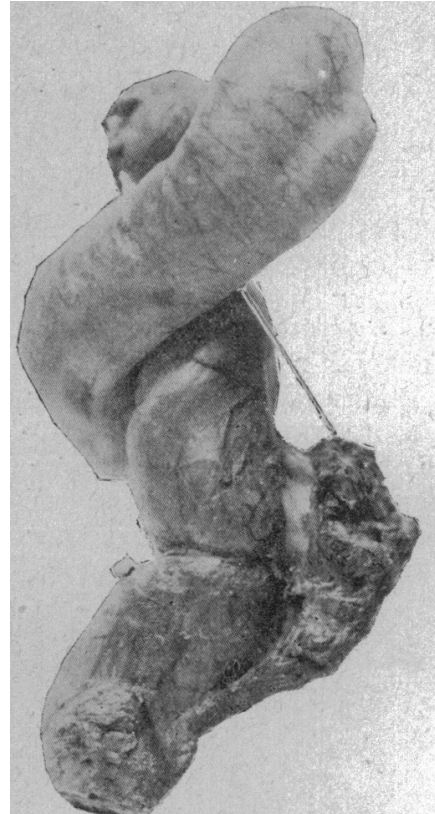

FIG. 13. - Side view of specimen shown in Fig. 12. The mesentery from sacrum and coccy $x$ to the reotum is fairly well shown, but is shown ing and drying having ghrunken it. ober aly toneum approaches to the anus.

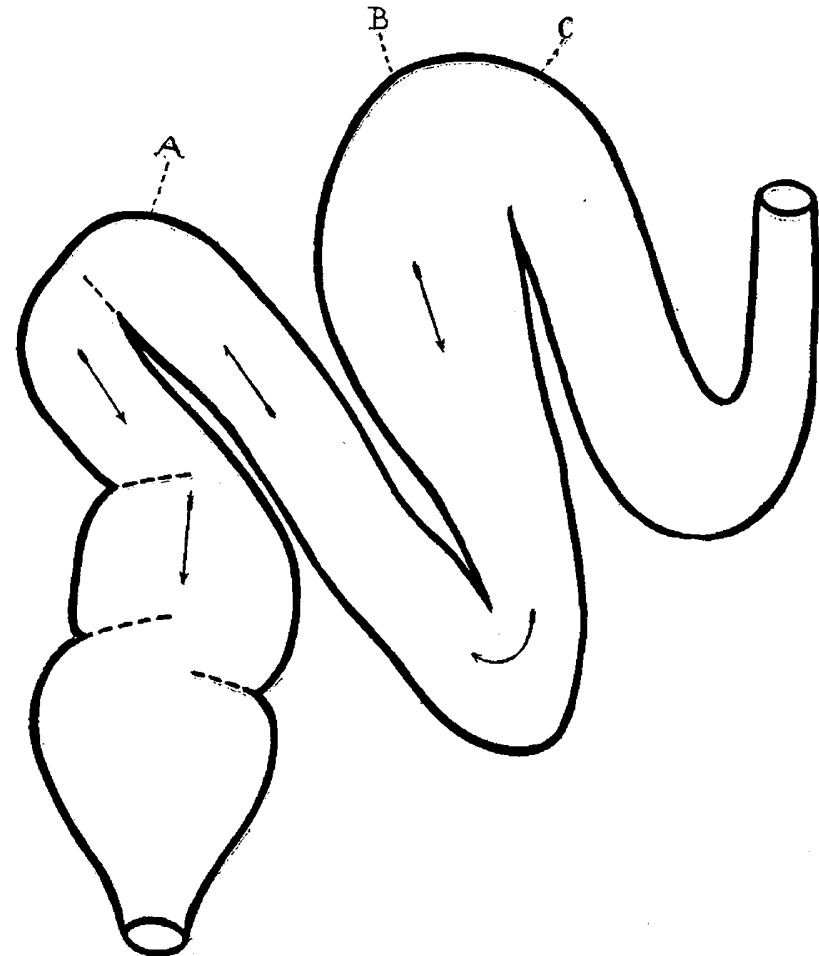

FIG. 15.-Diagrammatic of this gut in the empty state, therefore its flexions are not the same as those shown in the photographs. In the partly filled state, which is the condition about the time of defecation, the flexions and positions of these parts would be intermediate to those of the tiled and empty conditions. (The dotted

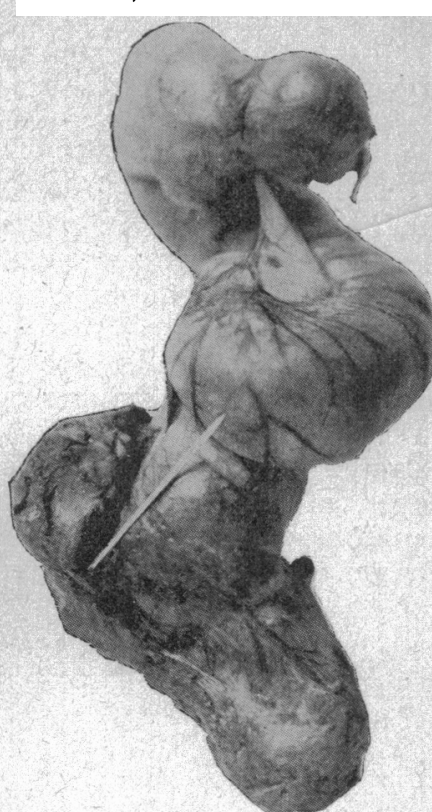

Frg. 14.-The reverse of the view shown in Fig. 18.

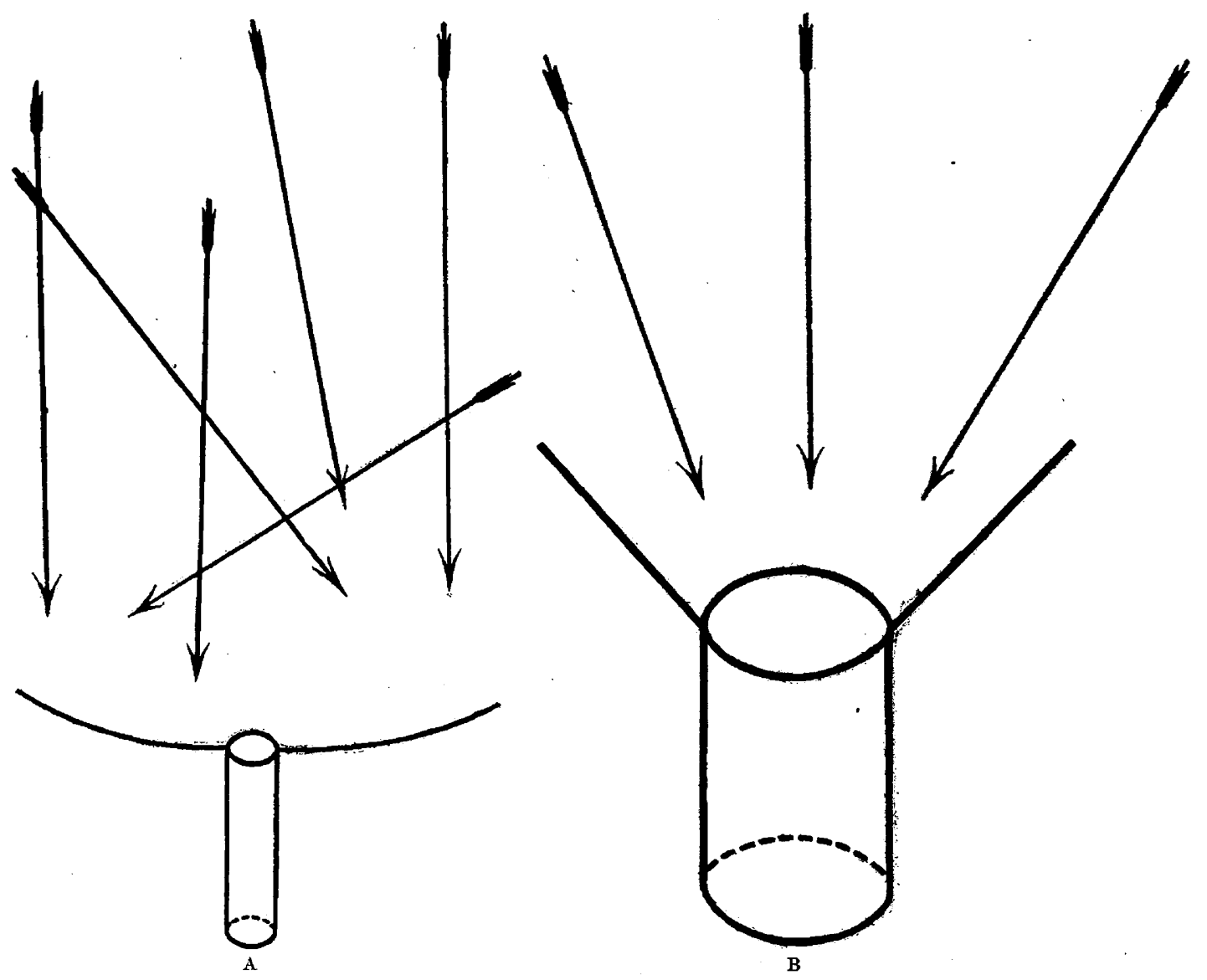

FIG. 16.-Diagrammatic, showing direction of forces and resistance in infant (A) and adult (B) and in defecation. 
posterior parts a vertical lane bare of peritoneum, from the borders of which the peritoneum is reflected in lateral directions. This uncovered part of the gut is not applied directly to the sacrum and coccyx, and there is a space between which is occupied by loose connective tissue. The distance from the dorsal parietes to the gut is variable here, being from one-half to one-fourth of an inch $(1.27$ to $.63 \mathrm{~cm}$.) At the beginning of the middle third there is usually a gradual decrease in the length of the peritoneal band as it descends till it is one-eighth or possibly but one-sixteenth of an inch (.32 or .16 cm.) in length at the last bone of the coccyx; it rapidly shortens from this point to its termination. The parietal peritoneum descends over the ischial tuberosities and approaches nearly to the ental sphincter muscle. In the newly born the peritoneum is situated within one-fourth inch $(.63 \mathrm{~cm}$. of the anal skin. (Observe plate 13.)

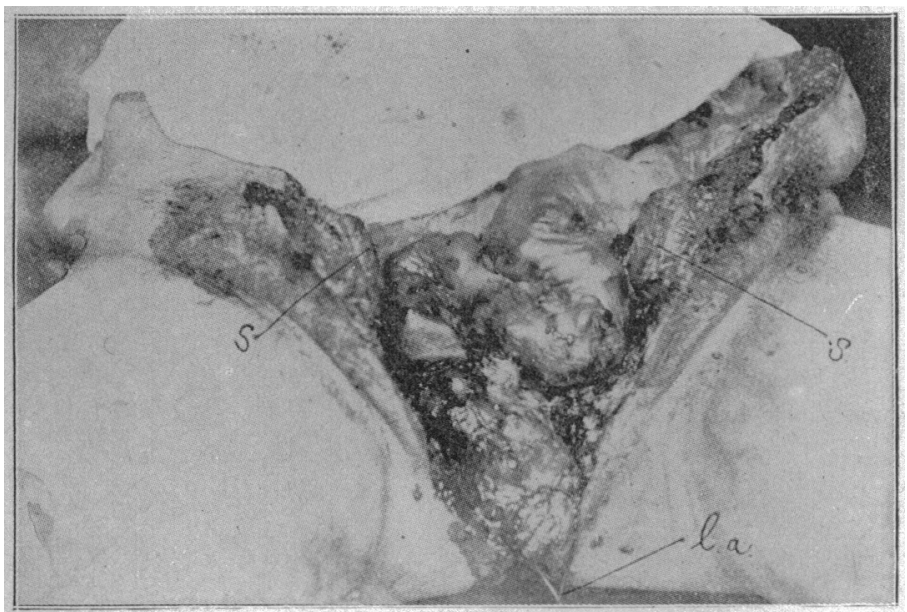

FIG. 17.-Photograph of a female cadaver showing, after laparosymphyseotomy and removal of bladder, uterus and adnexa, the upper rectum and sigmoid packed with scybala; ss, symphysis pubis; I a, ligature at anus. The shorter mesentery of the adult, perhaps, keeps that it may not escape the auxiliary forces of defecation. It is noticed that the sigmoid is more than normally distended. Quarter life size.

The disproportionate great length of descending colon and mesentery of the infant obviously contributes to the possibility of angulation of the gut.

We see in the presence in the child of lax and long, or relatively long, peritoneal ligaments, and in the great length of the descending colon and the consequent probability of numerous acute angulations in the infant sigmoid and rectum, and in the mobility of these parts within the abdomen, the possibility of development of a perfect adult mechanism for defecation. The essential features of this development are two; first, the growth of prostate or uterus and their supports which fix the lower rectum; and second, the down-growth and out-growth of the pelvic bones and the consequent conversion of mesenteric peritoneum to parietal peritoneum, which shortens the adult mesentery and in great measure fixes the upper rectum; thus the entire rectum is steadied to facilitate discharge when the mechanism of defecation is set in operation.

The diagrammatio plate 15 does not exaggerate these obstructive elements. The collateral muscles whioh assist in the performance of the act of defecation force the feces in the direction of the lower angle in each flexion, and in that flexion whose onward, or to be paradoxical, whose downward direction for the time points upward (plate 15 ), the auxiliary pressure is in the direction opposite to that of peristalsis.

Inspection of the pictures of the dried specimens reveals the angulations referred to, which may be expected to be more numerous the more segmentary the gut's contents.

The third feature obstructive to defecation in infants is the rectal valve. It is a feature and factor which not only is not recognized, but is one whose very anatomic existence has been most ingeniously and persistently disputed. It was imperfectly described as an anatomic feature of the rectum by $\mathrm{Mr}$. Houston in the Dublin Hospital Reports in 1830 , and many years later Dr. Walter A. Otis (1887) more practically demonstrated its presence; neither of these gentlemen, however, attributed to it the characteristic element of an anatomic valve, although bestowing upon it its proper name. A number of investigators have discovered

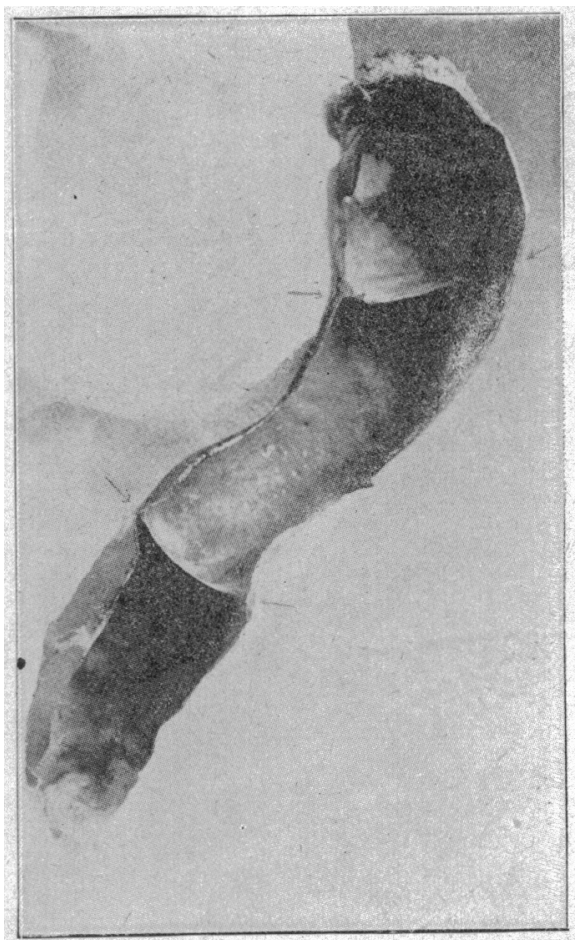

FIG. 18.-Interior view of the left half of the rectum of an adult Filled in the procto-colonoscopic posture, and distended only to the degree of normal atmospheric inflation. The anus is at the left of the picture. The valves are respectively two and one-half and seven inches 6.35 and $17.78 \mathrm{~cm}$.) from the anus. One-half life size.

this normal contracture of the ampulla and have miscalled it by various names and given it widely varying descriptions; but a greater number still deny its existence and critioally strive to dissolve away the imperfect evidence recorded in medical literature".

The pictures here shown of the dried specimens prove that in the infant the valve is such a matter of fact that its existence is no longer a matter for debate.

In each and every instance of more than three hundred persons examined by me these valves have been present, though in varying number and position in different subjects ${ }^{3}$. In most cases there are present three valves, in some there are four and in others there are but two.

I have marked that by some law of compensation

2 See Monograph by the writer on New Evidence that the Rectal Valve is an Anatomical Fact, John P. Morton and Compuny. Louisville. ee paper by the writer, Procto colonoscopy. etc., Mathew' Quarterly Journal of Rectal and Gastro-intestinal Diseases, July, 1896 
the fewer the number of valves in a given subject the better are they developed.

The infant specimens shown indicate that the valves are particularly well developed at birth. The specimen shown in plate 20 is marked by two valves in the so-called ampullar region, situated so close together that the middle portion of the rectum presents its longest diameter at right angles to the main direction of the gut. Another valve may be seen at the junoture of the upper portion and the sigmoid flexure.

The specimen shown in plate 18 is that of an adult, and presents two valves on the left and one on the right which is not exhibited. As these valves usually span more than half the circumference of the rectum it will be understood that in specifying their situation I refer to their central part. In many cases they are situated on the anterior and posterior walls, and their free borders are always directed a little obliquely, contributing a spiral direction to the channel of the reotum. The depth of the valve from free border to the

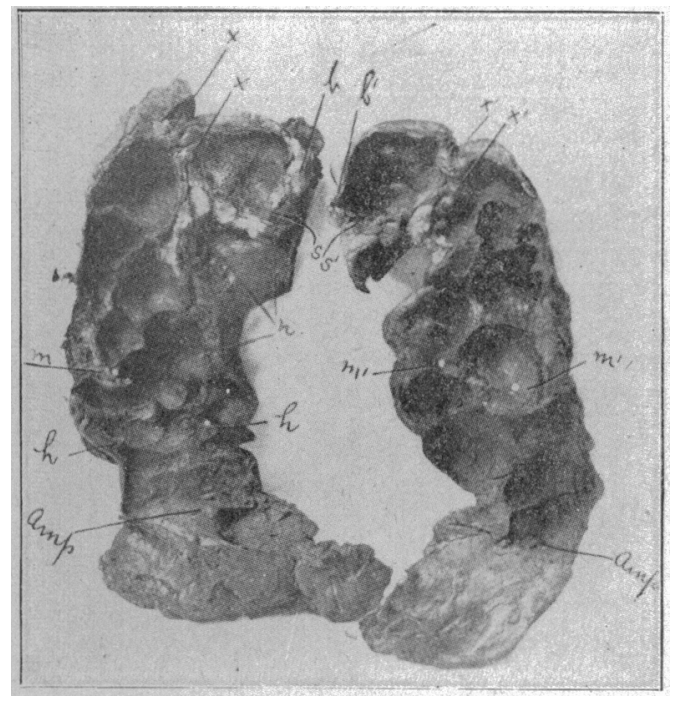

Fra. 19.-The rectum the same as is shown in Fig. 17, divided into anterior and posterior halves. Amp., anal end of ampulla; ss, sigmoidorectal communication: $x x, x x$, a semilunar valve dividing the midale and aper pemilunar valve ou the valve con of the empty state of the gut at this point: $b$ b', sigmoido rectal valve; $n$, portion of mesentery. One-half life size.

border attached, is usually about one-third the transverse diameter of the inflated rectum, and the valve is about one inch $(2.54 \mathrm{~cm}$.) in depth at its deepest point. Inspection of the photograph of the adult specimen (shown in plate 19) which was taken from the subject without disturbing its scybalous contents, shows that the valve may be found in systole (vide $\mathrm{xx}, \mathrm{x}^{\prime} \mathrm{x}$ ) or diastole (vide $\mathrm{m}, \mathrm{m}$ 'm').

The microscopic section which is here shown was taken from the middle of the lower valve of the adult specimen. (Plate 18.) In the illustration (plate 18) it is shown magnified fifteen diameters. The thickened state of the mucous membrane over the free border of the valve fortifies that point against the increased friction which that part must necessarily bear. Beneath it is noticeable the heavy layer of fibrous tissue which gradually diminishes till it is lost at the valve base. Bundles of circular muscular fibers are seen in the middle of the valve. At its base are seen arteries and veins for its special nutrition. This structural arrangement makes this organ the typical anatomic valve.
Speaking with anatomic accuracy the rectum is divided into as many portions, plus one, as there are valves in the rectal ampulla; for example, the rectal ampulla may be said to begin just below the angle which marks the termination of the sigmoid flexure. If there be two valves below this point, that part of the rectum above the higher one of these two valves must be considered the upper or first portion of the rectum, that part below the higher valve and extending to the lower, the middle or second portion, and that part of the rectum below the lower valve and terminating at the levator ani may be called the lower or third portion. Should a rectum have three valves, or perhaps but one, not counting the one at the sigmoido-rectal juncture. that subject's rectum accordingly should be considered to have four or two portions. Therefore if we recognize the existence of these valves in the rectum the conventional division into upper, middle and lower thirds, which is employed by the anatomists should be abandoned.

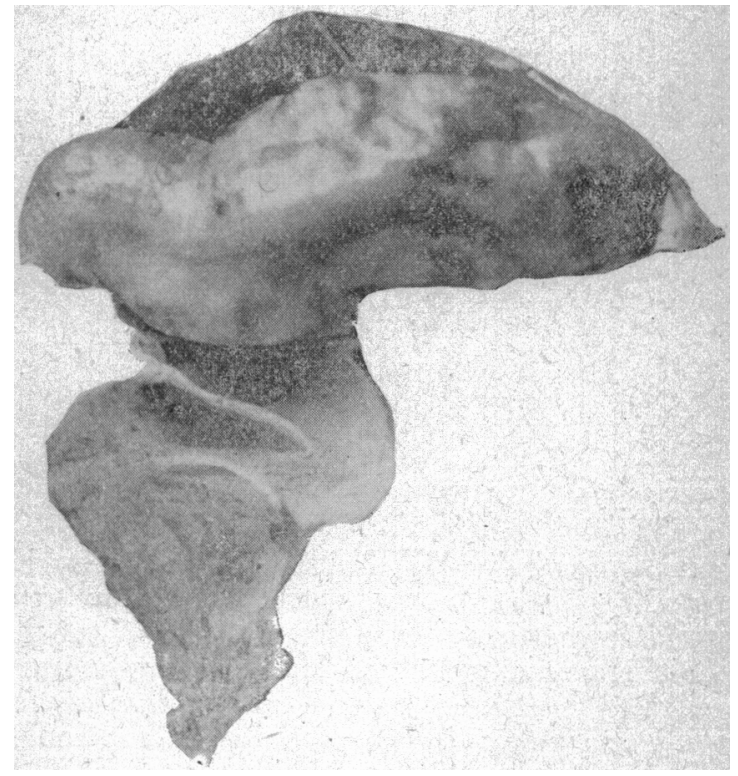

FIG. 20.-The rectum aud sigmoid of an infant aged two months. The photograph shows the interior of the anterior half. Portions of two valves are noticed at the middle part.

It must be readily seen that the presence in the rectum of such a structure as an anatomic valve would be essentially obstructive to the passage of feces.

In studying the physics of the rectum it is important that we recognize that the posterior wall from which the mesentery is reflected is less movable than other parts in the circumference, hence distention of the rectum not only tends to carry a given point of its wall away from a point opposite to it, but also carries it away from a given point cephalad or caudad. So it may be assumed that if the two valves situated at the ampullar middle of the cast-distended dried specimen (plate 20) are three-eighths of an inch $(.95 \mathrm{~cm}$.) sep. arated, and that the two opposite walls of the rectum in the portion bounded by these valves are one inch $(2.54 \mathrm{~cm}$.$) apart, that in a state of the gut's collapse$ or systole, the valves would be in contact, and thus afford a very definite obstruction to the descent of semi-solid feces.

The bony pelvic outlet in the infant is so contracted that the limits of anal expansion are such as to almost defeat the passage through it of other than fluid feces. It should be remembered that the normal average measurement from ischial tuberosity to ischial tuber- 
osity in the adult is about four inches $(10.16 \mathrm{~cm}$.), and it is a fact proven by our observation that the average transverse diameter of the newly-born infant's pelvic outlet is but a little more than one-half inch $(1.27 \mathrm{~cm}$.), the pubo-coccygeal measurement is even less. Those who are familiar with instrumental divulsion of the adult anus have observed that two and a he quarter inches $(6.35 \mathrm{~cm}$.) is the average limit of lateral separation of the anus, the remaining portion of

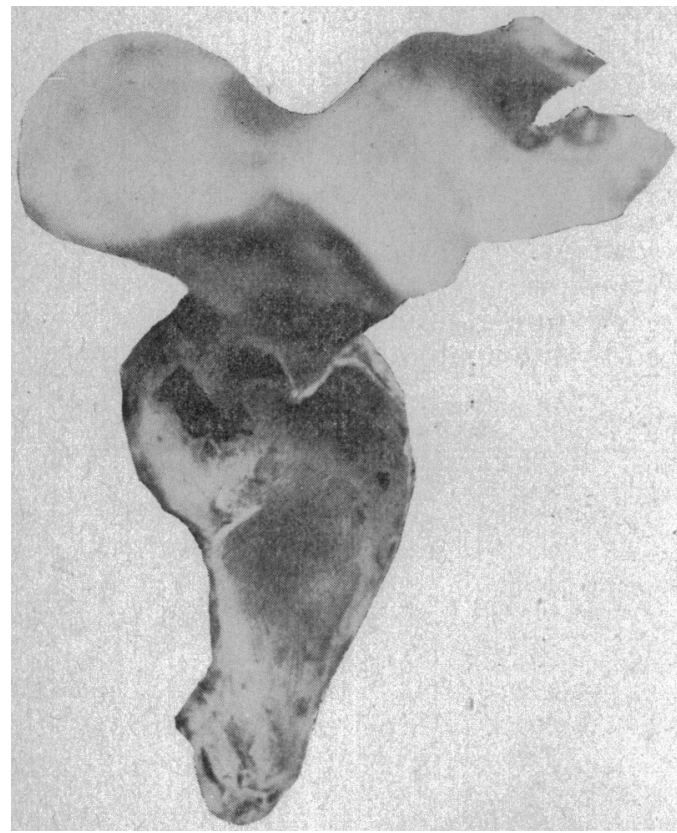

FIG. 21.-The interfor view of the opposite posterior half of the rectum shown in Fig. 20, the two valves shown in Fig. 20 being continued toward each extremity of the ampulla. The sigmoid is out of focus.

the bony outlet being filled with the compressed soft tissues of the ischio rectal space. Therefore it may be estimated that nine-sixteenths at most, of the diameter of the pelvic outlet is the reasonable limit of expansibility of the anus for the passage of feces. Applying this calculation to the infant we find that if the ischial tuberosities are one-half inch $(1.27 \mathrm{~cm}$.) separated, that the anal expansibility is but five-six-

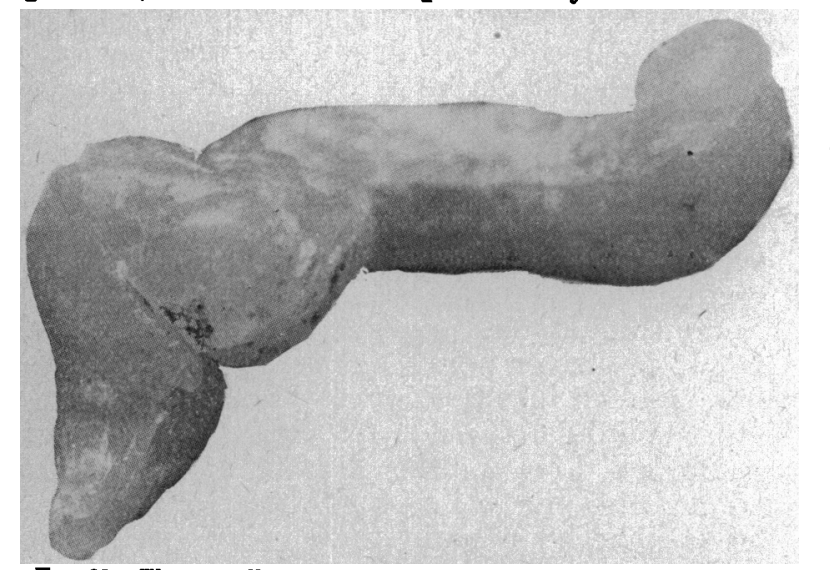

Fig. 22.-Tho paraffin cast removed from the gut pictured in Figs.

teenths of an inch $(.79 \mathrm{~cm}$.), which is, as we kuow, the diameter of a No. twenty-two sound (French scale). Reference to the paraffin cast of the infant gut (plate 22) indicates that the average distensibility of the sigmoid flexure and rectal ampulla, in which the feces when firm are formed, is four or five times that of the anal expansibility; thus it is readily perceived that compared to the adult the juxtaposition of the ischial tuberosities in the infant supplies a most obstinate obstructive factor in defecation.

To collate in brief:

1. The muscular development of the adult rectum and lower sigmoid is plainly apparent in the plates here exhibited of the fresh specimens. A deficient muscularity is observed in the infant specimens.

2. The peritoneum of these parts in the adult is observed to be relatively, very considerably shorter than that in the infant.

3. The rectal valves appear to bear the same proportion to the gut in both adult and infant, but when we remember the difference in muscular development in the two the disproportionate resistence of the valve in the infant rectum is obvious.

4. The anal expansibility is remembered as adequate in the adult, and is seen to be deficient in the infant.

Co-relative to the facts just stated we must recognize that the adult rectum has resident within its own wall a powerful expulsive muscular mechanism; that the shortening of the mesentery holds the upper rectum

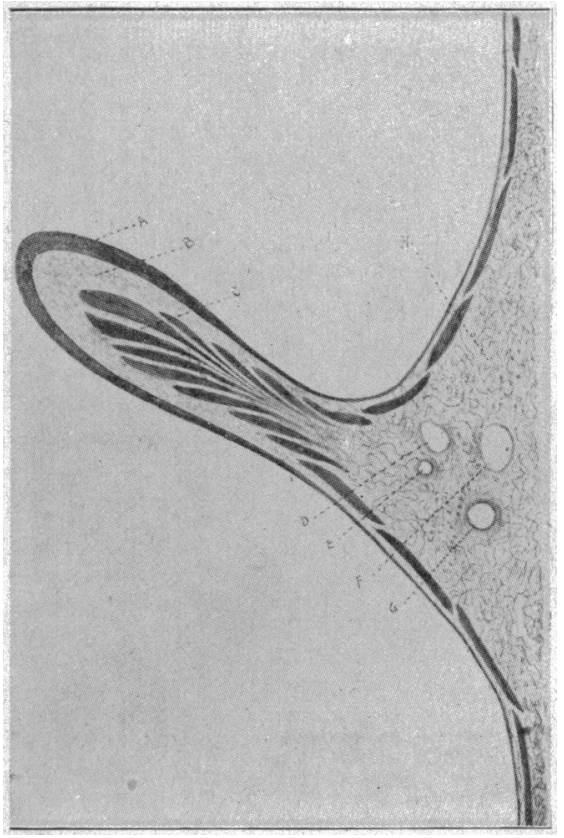

Frg. 23.-A semilunar valve taken from the specimen shown in Fig. 18, drawn as seen under a glass magnifying fifteen diameters. $A$, muc fibres; D, vein; E, artery; $F$, vein; $G$, artery; $H$, areolar and adipose tissue.

steady under the applied auxiliary forces; that the angulations of the sigmoid are not necessarily obstructive, though in a desirable measure retardative; that the forward incline of the lower sacrum and coccyx behind, and the development of the uterus and prostate and their inherent supports in front, provide the lower adult rectum with a firm funnel-like arrangement which guides the feces directly upon the os internum of the anus; that the valves divide the feces into portions to facilitate their separate successive discharge, and finally in sequence, that the physiologic descent $t^{5}$ of the structures of the ischio-rectal space reduces this last resistence to the minimum in adult defecation.

Straining, the ruptures and prolapses, constipation,

see Andrews' Surgery of the Rectum, table of peritoneal relations to adult rectum. 
retention of feces and the multitudinous consequent ills have demanded our patient inquisitive consideration; and this study forces the conclusion, I believe, that the individual's escape is ultimately assured by process of development, but that for the normally formed infant, the physician will find the solution of the problem of difficult defecation in the solution of the stool.

1077 Prospect Street.

\section{MEDICINE AND THE STATE.}

From a paper read before the Contemporary Club, I)avenport, Iowa, Nov. 18,1897

BY C. H. PRESTON, A.M., M.D. DAVENPORT, IOWA.

Just half a century has passed since, in 1847 , Liverpool, and soon after, London-fearing a cholera invasion-appointed the first medical officers of health in Great Britain. ${ }^{1}$ The next year, the dread scourge having made its appearance, a central board was established, and today, to quote Palmberg's Public Health: "Of all the countries of the civilized world none has a sanitary code so complete and so precise as England." That its provisions are respected by all and, as a rule, religiously observed, he rightly ascribes to the fact that they are the work of the people themselves and not mere administrative orders but little understood.

The sanitary administration of England is placed, in accordance with the public health act of 1875 , in the hands of a government board acting together with boards locally established. The former consists of a president appointed by the crown, a parliamentary and a permanent secretary, together with various secretaries and high officials of state acting as advisory members. Its work is divided among the general departments of poor-law administration, the sanitary regulation of buildings, of factories, of sewers and streets, water supply, vaccination and other matters pertaining to public health,

Complete as is its present organization however, there is a movement now on foot to place it on a yet higher plane. ${ }^{2}$ A motion will soon be made in Parliament, it is said, that "in the opinion of the House of Commons it is desirable that a department of public health be constituted and that the same be under the charge of a responsible minister having a seat in Parliament."

In this country the first step in state medicine was taken in 1849 , when a commission was appointed by the governor of Massachusetts to prepare for a sanitary survey of that State. ${ }^{3}$ But the Massachusetts State Board of Health, the first active State board to be formed in the Union, was not established until 1869. Meanwhile, in 1865, the State of Louisiana, in order the better to cope with an invasion of yellow fever, had appointed what was actually the first State board, though it possessed but very limited powers. At the present time all but ten of our fifty-one Federal divisions, including the District of Columbia, have each its more or less active board of health, all working together for the general welfare, while local boards under them, everywhere co-operate for the sanitation of cities and towns. ${ }^{4}$ The ten exceptions are Alaska, Arizona and the Indian Territory, Georgia, Idaho, Montana, Oregon, Texas, Utah and Wyoming. Georgia formerly possessed a State Board, but allowed it to lapse for lack of an appropriation. Texas, though without a State Board, maintains a State Officer of Health.
But the United States has today no national board or department of health. The first step was indeed taken toward the nationalization of health in this country March 3, 1879, when an act of Congress to prevent the introduction of contagious or infectious diseases and to establish a national board of health was approved. ${ }^{5}$ The board thus authorized, however, had but four years of active existence. It consisted of eleven members, seven appointed by the President and one each detailed from the Medical Department of the Army, the Medical Department of the Navy, the Marine-Hospital Service and the Department of Justice. It had no definite term of office and its duties, beyond gathering and disseminating information, were arvisory merely. An act approved June 2 of the same year somewhat extended its powers but was limited to the four years succeeding, at the end of which period-Congress refusing to re-enact-the board ceased practically to exist and the act establishing it was at length formally repealed Feb. 15, 1893.

The place of a national board is now filled in part by the Marine-Hospital Service, a bureau of the Treasury Department, aided by the Bureau of Animal Industry of the Agricultural Department.

The Marine-Hospital Service was established in 1798 , but placed on its present basis in 1871." Its purpose was to care for the sick and disabled seamen of the merchant marine. In default of a national department of health, however, other duties and responsibilities have from time to time devolved upon it, giving it an anomalous position in the government, without definite scope or determinate power. The Revenue and Life-Saving Services depend upon it for the physical examination of their officers and men; it assists the Steamvessels Inspection Service by examining pilots for color-blindness; it is entrusted with the execution of the national quarantine laws, the management of the eleven national and the inspection of all local quarantine stations and with power to enforce inter-state quarantine regulations; it investigates reported cases of epidemic disease, collects and disseminates mortality statistics and sanitary information and makes investigations (bacteriologic, etc.) into the causes of disease; it examines immigrants for the existence of contagious diseases and has service in consul's offices at foreign ports to secure accuracy of bills of health given.

The Bureau of Animal Industry investigates as to the existence of communicable diseases of stock, superintends measures for their extirpation and pursues investigations as to their nature and means of prevention. It has charge of the inspection of import and export cattle, vessels of export and stock quarantine stations, and supervises the inter-state movements of live stock and their slaughtered products.

But when all is said, both bureaus remain and must remain subordinate organizations, subservient in part to other interests than those of health.

Another organization which has done and is doing much to promote and harmonize sanitary work in and between the States is the American Public Health Association, a body composed of the leading sanitarians of the United States, Canada and Mexico. But it is wholly without government authority or support. The need for a sanitary head with which other nations could confer and co-operate authoritatively and promptly, which should co-ordinate, supplement and assist, but in no way supplant the several State boards, has long been felt; and various bills for estab. 